EImar Kraus $\bullet$,

Sibylle Schneider-Schaulies $\bullet$, Masayuki Miyasaka ${ }^{\top}$, Takuya Tamatani ${ }^{\nabla}$ and Jonathon Sedgwick

Institute for Virology and Immunobiology ${ }^{\bullet}$, The University of Würzburg, Würzburg and Department of Immunology ${ }^{\nabla}$, The Tokyo Metropolitan Institute of Medical Science, Tokyo

\section{Augmentation of major histocompatibility complex class I and ICAM-1 expression on glial cells following measles virus infection: evidence for the role of type-1 interferon*}

\begin{abstract}
An intracellular staining procedure for the cytoskeletal marker, glial fibrillary acidic protein of astrocytes, has been developed which allows flow cytometric phenotyping of astrocytes within complex mixtures of glial cells. Employing this technique, we show here that measles virus infection of rat mixed glial cell cultures results in a rapid augmentation of major histocompatibility complex (MHC) class I and ICAM-1 on the majority of astrocytes in culture. MHC class I levels are increased on macrophages/microglia but ICAM-1 expression is not normally affected on this cell type. Some MHC class II induction is also observed after virus infection but only on astrocytes. A type-I interferon (IFN)-inducible protein, $\mathbf{M x}$, was identified in cultured glial cells after infection. Qualitatively comparable MHC class I and ICAM-1 enhancement after addition of type-I IFN, supports the conclusion that this cytokine(s) released as a result of virus infection, is responsible for alterations in the expression of molecules on glial cells, that are involved in $\mathrm{T}$ cell recognition. Astrocytes after viral infection were more susceptible to alloantigen-specific cytotoxic $T$ lymphocytes and cytotoxic $T$ lymphocyte activity was substantially reduced in the presence of $m A b$ specific for MHC class 1, ICAM-1 and LFA-1 but not MHC class II. The relevance of these findings to $T$ cell recognition of virus-infected cells in the central nervous system is discussed.
\end{abstract}

\section{Introduction}

Measles virus (MV) is a common human pathogen responsible for a range of diseases from acute $\mathrm{MV}$ infection of childhood through to severe infections of the central nervous system (CNS). Within this latter category, disease types vary from acute measles encephalitis to subacute sclerosing panencephalitis in which onset of clinical disease generally occurs many years after recovery from normal acute MV infection (reviewed in [1]). An effective immunological response to such infections of the CNS is undoubtedly complex and hampered by the relative lack of MHC [2] and adhesion molecule expression (such as ICAM-1, [3]) in this tissue. Nevertheless, the immune system under normal circumstances apparently copes with the vast majority of viral infections in the CNS (reviewed in [4]).

How is this effective immune surveillance achieved? First, it is possible that antigenic peptide is displayed on the luminal face of brain vascular endothelial cells. These cells

[I 9710]

\footnotetext{
* This work was supported by grants from the Bundesministerium für Forschung und Technologie and the Deutsche Forschungsgemeinschaft.
}

Correspondence: Jonathon D. Sedgwick, Centenary Institute of Cancer Medicine and Cell Biology, The University of Sidney, Sidney, NSW 2006, Australia

Abbreviations: MV: Measles virus CNS: Central nervous system GFAP: Glial fibrillary acidic protein are constitutively $\mathrm{MHC}$ class $\mathrm{I}^{+}$and so, at least for virus-specific $\mathrm{CD}^{+} \mathrm{T}$ cells, this could be a point of recognition. LCMV-derived peptides for example, are almost certainly recognized by $\mathrm{CD} 8^{+} \mathrm{T}$ cells at this site [5]. Second, there is now good evidence to suggest that the brain is patrolled by activated $\mathrm{T}$ cells nonspecifically crossing the blood-brain barrier [6, 7]. However, T cell recognition of viral peptides in the context of MHC class I or class II molecules is unlikely to occur readily in the parenchyma of the CNS. This is an important caveat as it is cells such as astrocytes, oligodendrocytes and neurons that are the foci of virus infection in subacute sclerosing panencephalitis for example [1]. Much attention has been focused on the ability of certain inflammatory cytokines, in particular IFN- $\gamma$ and TNF- $\alpha$, to induce and up-regulate MHC and ICAM-1 expression on glial cells $[7,8]$ but the presence of these factors in the CNS would indicate that an inflammatory process has already been initiated. In the absence of such inflammation, which is a far more likely situation early after the virus has entered the CNS, inflammatory cytokine-mediated up-regulation of MHC and ICAM-1 expression on glial cells cannot be considered a viable mechanism for induction of conditions that would enable the infected cell to be recognized by $\mathrm{T}$ lymphocytes.

For virus infections of the CNS, one possibility is that the virus itself directly or indirectly induces or enhances the expression of cell-surface molecules important for $\mathrm{T}$ cell recognition. A number of reports have already been made regarding the up-regulation of MHC class I on a variety of infected cell types ([9-12], reviewed in [13]) and also MHC class II induction on otherwise negative cells, including astrocytes $[11,12,14]$. The mechanisms underlying the alteration of MHC expression in virus-infected cells are 
unclear. In the present study we have examined the augmentation of MHC antigens and the adhesion molecule ICAM-1 on mixed glial cells infected in vitro with MV. The results clearly indicate that virus infection alone is sufficient to consistently increase astrocyte MHC class I and ICAM-1 expression and that these phenotypic changes are probably mediated by MV-induced release of type-I IFN.

\section{Materials and methods}

\subsection{Animals}

Full-term pregnant rats and 8- to 10-week-old female rats were obtained from Zentralinstitut für Versuchstierzucht, Hannover, FRG. All animals were SPF and from the Lewis (LEW, RT1 $1^{l}$ ) and BDII (RT1 $\left.{ }^{u}\right)$ strains.

\subsection{Monoclonal and polyclonal antibodies}

Mouse mAb were: MRC OX1 (anti-rat CD45; leukocyte common antigen, [15]), MRC OX6 (anti-rat monomorphic MHC class II, RT1B (I-A), [16]), MRC OX18 (anti-rat monomorphic MHC class I, RT1A, [17]), MRC OX21 (anti-human C3bi and not rat cells, [18]), MRC OX42 (anti-rat CD11b/c, [19, 20]), WT.1 (anti-rat CD11a, LFA-1, [20]), 1A29 (anti-rat CD54, ICAM-1, [21]), mGalC (antigalactocerebroside, [22]) and F227 (anti-MV nucleocapsid (N) protein, generated by Uwe Liebert of this Institute). MRC OX21 and F227 tissue culture SN were provided by Don Mason, Oxford, GB and by Uwe Liebert, respectively. All other $\mathrm{mAb}$ were prepared as tissue culture $\mathrm{SN}$ or ascites fluid from hybridomas obtained from Alan Williams, Oxford, GB (OX1,-6,-18,-42) and B. Ranscht (mGalc). MRC OX6, MRC OX18, 1A29 and WT.1 IgG were purified from ascites fluid by standard procedures. MRC OX6 and MRC OX18 IgG were biotinylated as described [23]. Rabbit anti-glial fibrillary acidic protein (GFAP) was from Dakopatts (Hamburg, FRG) and normal rabbit IgG from Dianova (Hamburg, FRG). AP5 (rabbit anti-mouse Mx protein that strongly binds rat $\mathrm{Mx}-1,[24])$ was kindly provided by Dr. Otto Haller, Institute for Virology, Freiburg, FRG. FITC-conjugated rat anti-mouse IgG, TRITCconjugated goat anti-rabbit IgG, PE-conjugated donkey $\mathrm{F}\left(\mathrm{ab}^{\prime}\right)_{2}$ anti-rabbit IgG (pre-absorbed against mouse and rat Ig) and PE-conjugated streptavidin were from Dianova.

\subsection{Cell lines, cytokines and miscellaneous reagents}

Mycoplasma-free African green monkey kidney fibroblast (CV1) cells were obtained from the European Collection of Animal Cell Cultures, Porton Down, GB. A GFAP- isolate of the human glioma (D-54) cell line [25] was obtained from R. Brinkmann of this Institute. Both lines were maintained in DMEM-5\% FCS. rIFN- $\gamma$ was kindly provided by Dr. P. H. Van der Meide, Rijswijk, The Netherlands and human rTNF- $\alpha$ was from Boehringer, Ingelheim, FRG. Purified rat type-I IFN (mostly IFN- $\alpha$, some IFN- $\beta$ ), n-octyl$\beta$-D-glucopyranoside and BSA were from Sigma Chemical Company, Deisenhofen, FRG.

\subsection{Virus preparation}

MV (Edmonson strain) was produced and titrated on CV1 cells by standard procedures. Additionally, mock-infected $\mathrm{CV} 1$ cells were incubated at $33^{\circ} \mathrm{C}$ for 3 days to produce control SN.

\subsection{Glial cell preparation and experimental procedures}

Primary enriched astrocyte cultures consisting of $90 \%-95 \%$ $\mathrm{GFAP}^{+}$cells with $<2 \%$ microglia present (as defined by CD45 [26] and MRC OX42 [19, 26] expression), were prepared from the meninges-stripped cerebral lobes of 1- to 2-day-old Lewis strain rats as described [27]. Cells were harvested from flasks and either seeded into wells of 6-well plates, directly stained for FCM or seeded into wells of 24-well plates containing glass coverslips to enable fluorescence microscopic analysis. Mixed glial cultures were prepared as above but were seeded at high density (usually around eight times that used to prepare enriched astrocyte cultures) directly into wells of 6-well or 24-well plates and were used within 10 days of culture establishment. The major cell types constituting these latter cultures are described in Sect. 3. For virus infection, medium was replaced with $1 \mathrm{ml}$ (6-well plates) or $100 \mu \mathrm{l}$ (24-well plates) mockinfected CV1 SN or MV at a concentration of $3 \times 10^{6}-5 \times$ $10^{6} \mathrm{PFU} / \mathrm{ml}$ (corresponding to a multiplicity of infection of between 1 and 3 ) for $1 \mathrm{~h}$ at $37^{\circ} \mathrm{C}$, then the $\mathrm{SN}$ were removed and fresh medium was added. This is designated day 0 . In most experiments, virus or mock SN were added as above to these same cell cultures $24 \mathrm{~h}$ later and again $48 \mathrm{~h}$ later. After a further $24 \mathrm{~h}$, the cells were usually harvested for flow cytofluorographic analysis or coverslips stained for fluorescence microscopic analysis. rTNF- $\alpha$, rIFN- $\gamma$ or typeI IFN at a final concentration of $10 \mathrm{U} / \mathrm{ml}$ were added to glial cell cultures alone or together with mock or virus-containing supernatants (rTNF- $\alpha$ only) as detailed in Sect. 3.

\subsection{Cell staining}

\subsubsection{Fluorescence microscopy}

Cells adherent to glass coverslips were washed, fixed for 10 min with $3 \%$ paraformaldehyde and permeabilized by treatment with $0.5 \%$ Triton $\mathrm{X}-100$ for $5 \mathrm{~min}$. After blocking with $10 \%$ BSA in $0.025 \mathrm{M}$ Tris buffer for $15 \mathrm{~min}$ antibodies aginst Mx, GFAP or MV and appropriate FITC-or TRITCcoupled second antibodies were added. Coverslips were mounted in glycerol and viewed with a Leitz (Giessen, FRG) Aristoplan fluorescence microscope.

\subsubsection{Internal labeling and flow cytofluorographic analysis}

Cells were removed from culture flasks or 6-well plates by standard trypsin/EDTA treatment and washed in cold PBS $0.2 \%$ BSA $10 \mathrm{~mm}$ sodium azide. For extracellular staining, unlabeled mouse $\mathrm{mAb}$ (negative control or test) was added to samples of $3 \times 10^{5}-5 \times 10^{5}$ cells for at least $30 \mathrm{~min}$ on ice then the cells washed, resuspended in FITC-conjugated rat anti-mouse Ig and incubated on ice for a further $30 \mathrm{~min}$. After washing, the surface labeled cells were assessed 
directly or permeabilized employing a modification of a method described by Halldén et al. [28]. Each aliquot of cells was resuspended in $400 \mu \mathrm{l}$ ice-cold formalin $[0.5 \%$ (v/v) in PBS without $\mathrm{Ca}^{2+}$ and $\mathrm{Mg}^{2+}$ ] and incubated for $30 \mathrm{~min}$ on ice. After washing, the cells were resuspended in $500 \mu \mathrm{l}$ n-octyl- $\beta$-D-glucopyranoside $(4 \mathrm{mg} / \mathrm{ml}$ in $0.15 \mathrm{M}$ PBS), incubated for $7 \mathrm{~min}$ at room temperature then washed and pelleted. The cells were resuspended in $25 \mu \mathrm{l}$ of $10 \% \mathrm{BSA}$ in $0.025 \mathrm{M}$ Tris buffer and incubated for $15 \mathrm{~min}$ on ice. To this was added $25 \mu \mathrm{l}$ rabbit IgG anti-GFAP or as a control, normal rabbit IgG at the same concentration and incubated for $45 \mathrm{~min}$ on ice. After washing, the cells were resuspended in $50 \mu \mathrm{l}$ PE-conjugated donkey anti-rabbit IgG diluted in PBS $1 \%$ BSA $10 \%$ normal rat serum $10 \%$ normal mouse serum and incubated for $1 \mathrm{~h}$ on ice. After further washes, $10^{4}$ live gated events were analyzed on a FACScan $^{\mathrm{TM}}$ (Becton Dickinson, Heidelberg, FRG).

\subsection{CTL assays}

Alloreactive BDII CTL against LEW were generated in an MLR by mixing and incubation for 5 days $2.5 \times 10^{5}$ irradiated LEW LN stimulator cells with $5.0 \times 10^{5}$ responder BDII LN cells per U-bottom well. Target cells were either LEW or BDII Con A blasts or LEW astrocytes which had been mock-or virus infected as described above and recovered $72 \mathrm{~h}$ after initial (d0) infection. ${ }^{51} \mathrm{Cr}$-labeled target cells were pre-incubated for $40 \mathrm{~min}$ on ice either in medium alone or with blocking $\mathrm{mAb}$ (see Sect. 3), added to titrated CTL effector cells in 96-well V-bottom plates and incubated for $5 \mathrm{~h}$ at $37^{\circ} \mathrm{C}$. Data shown is percent of total release after subtraction of spontaneous release. With T cell blast targets, spontaneous release was $<30 \%$ while with astrocyte targets, it varied between $20 \%$ and $40 \%$.

\section{Results}

\subsection{Internal labeling of astrocytes}

The cytoskeletal protein, GFAP, is the most reliable marker for astrocytes both in vivo and in vitro [29] but because this is an intracellular molecule, detection requires permeabilization of the cell membrane. The protocol used here offers a number of advantages over other standard fixation/permeabilization procedures. Fig. $1 \mathrm{~b}$ illustrates the low level of nonspecific staining by normal rabbit IgG (control), while addition of anti-GFAP produced a strong positive shift in around $90 \%$ of the cells. A comparable figure for $\mathrm{GFAP}^{+}$cells in this population was obtained by standard immunofluorescence microscopy. Untreated astrocytes (Fig. 1 a) were not stained with anti-GFAP. Other procedures tested, including paraformaldehyde fixation and permeabilization with Triton X-100, were unsatisfactory. The same scatter shift (Fig. $1 \mathrm{~b}$ ) was seen after $0.5 \%$ formalin fixation alone (not shown).

\subsection{Astrocyte detection in cell mixtures}

To study the effects of MV infection on glial cell expression of $\mathrm{MHC}$ and adhesion molecules in vitro, mixed glial populations were generally used rather than enriched astrocytes to more closely mimic the in vivo situation.

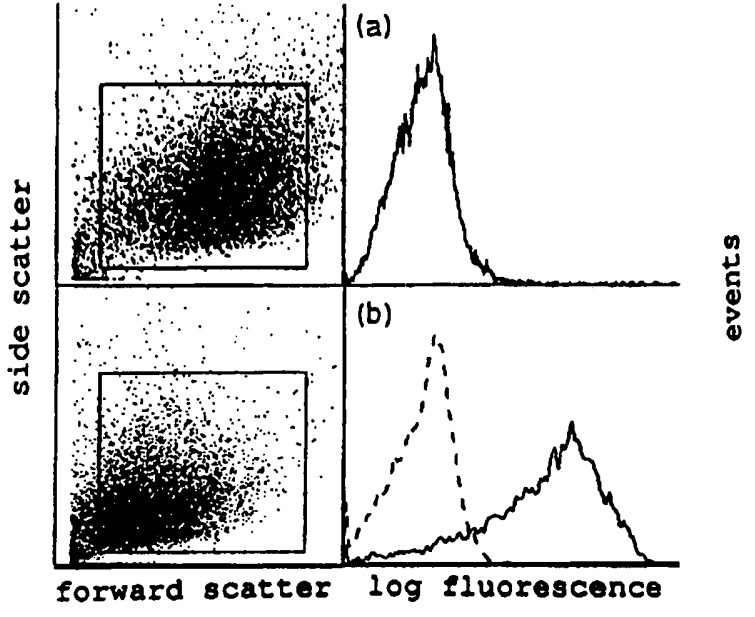

Figure 1. GFAP staining of astrocytes for FCM. Enriched astrocyte cultures were stained for GFAP (solid line) or an equivalent concentration of normal rabbit IgG (dashed line). (a) Unfixed, non-permeabilized; (b) $0.5 \%$ formalin fixed, n-octyl- $\beta$-D-glucopyranoside permeabilized as per Sect. 2.6 .
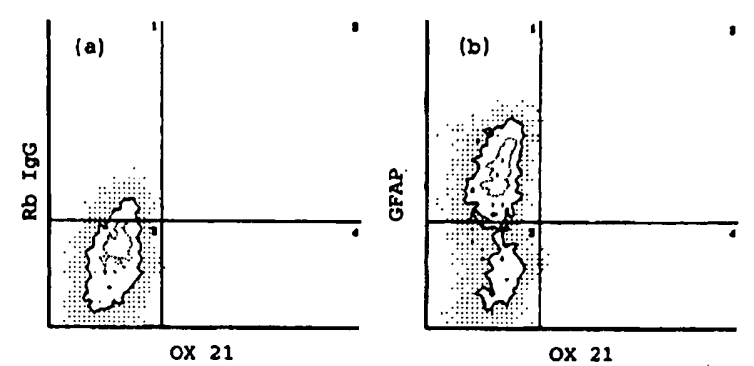

ox 21
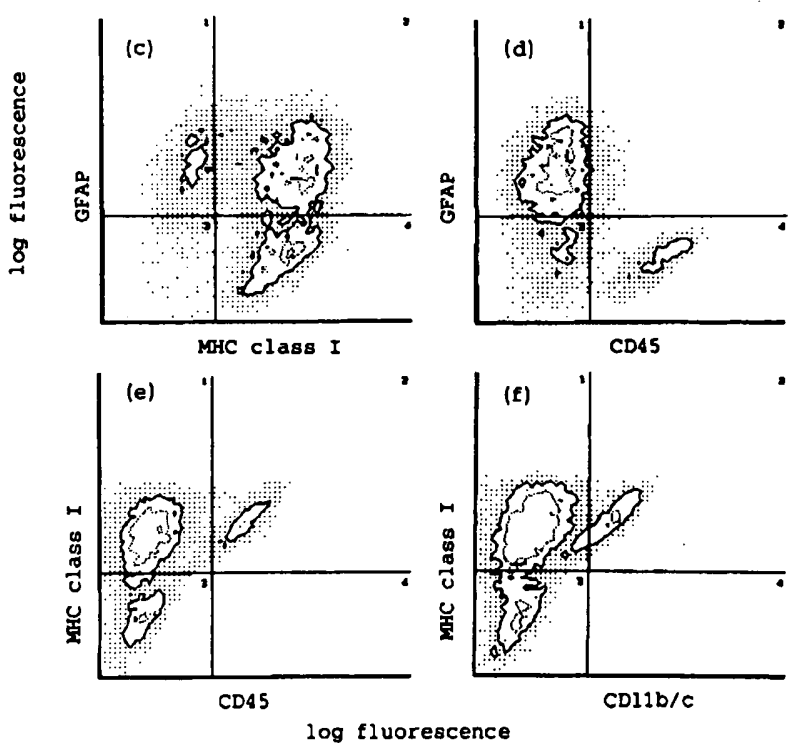

Figure 2. Astrocyte and microglia content of mixed glial cultures revealed by two-color FCM and internal staining. (a-d) Cells were stained exactly as described in Sect. 2.6 for surface markers (MHC class I and CD45 with MRC OX21. as negative control) then fixed and permeabilized and stained internally [GFAP or rabbit (Rb) $\mathrm{IgG}$ as negative control]. (e, f) Cells were double surface stained for CD45 or CD $11 \mathrm{~b} / \mathrm{c}$ and MHC class I, the latter detected with biotinylated MRC OX18 mAb and PE-streptavidin. 
Table 1. Detection of astrocytes in cell mixtures ${ }^{a)}$

$\begin{array}{lcccc} & \text { Sample: } & 1 & 2 & 3 \\ \text { Stained input } & \text { Astrocytes (\%) } & 30 & 50 & 70 \\ \text { population } & \text { D-54 cells (\%) } & 70 & 50 & 30 \\ \text { Positive cells by } & \text { GFAP+ (\%) } & 24 & 53 & 62 \\ \text { FCM } & \text { GFAP- (\%) } & 76 & 47 & 38\end{array}$

a) Cells from enriched rat astrocyte cultures and GFAP- D-54 glioma cells were mixed in the proportions shown, then fixed, permeabilized and stained for GFAP as described in Sect. 2.6 and analyzed by FCM.

Table 1 first illustrates that $\mathrm{GFAP}^{+}$rat astrocytes could be accurately quantitated by FCM when mixed with GFAP(D54) cells. Fig. 2 clearly demonstrates the versatility of this method for detection of subpopulations of cells in a normal mixed glial culture 8 days after establishment.

Cells were cultured in the presence of FCS and so, as expected [29], cell differentiation was driven in the direction of astrocytes. Astrocytes in situ are MHC class $\mathrm{I}^{-}$or express extremely low levels of this molecule [2] but become MHC class $\mathrm{I}^{+}$during cell culture [30]. The GFAP ${ }^{+}$ cells shown in Fig. 2 c split into MHC class $\mathrm{I}^{+}$(around $50 \%$ ) and class $\mathrm{I}^{-}$(around $20 \%$ ) populations. It is likely that the MHC class $\mathrm{I}^{-} \mathrm{GFAP}^{+}$cells are the more recently differentiated ones. The MHC class I+ GFAP- cells (around $25 \%$ ) are mostly $\mathrm{M} \Phi /$ microglia $(15-18 \%)$ which are $\mathrm{CD} 45^{+}$ (Fig. 2d and e) and CD11b/c ${ }^{+}$(Fig. 2f). There are two populations that remain undefined. A round $5 \%$ of the cells are both MHC class $\mathrm{I}^{-}$and GFAP- (Fig. $2 \mathrm{c}$, box 3 ). There are also some cells that are MHC class $\mathrm{I}^{+}$(Fig. 2 c, box 4 ) but are not $\mathrm{M} \Phi / \mathrm{microglia}$, at least as defined by CD 45 and CD11b/c staining. Some of these cells could be oligodendrocytes but generally, $<5 \%$ galactocerebroside-positive cells (oligodendrocytes) were detected in these cultures.

\subsection{MV infection augments expression of MHC class I and ICAM-1 on astrocytes}

Within 4 h of virus addition on day 0 to mixed glial cultures, the majority of cells were infected, as determined by immunofluorescence microscopic detection of cytoplasmic viral nucleocapsid protein. By $24 \mathrm{~h}$, generally $<10 \%$ of the cells were infected by this same criterion and on the basis of cell morphology, the majority of these were astrocytes. In view of previous studies from this laboratory on the ability of both infectious and non-infectious viral particles to induce or enhance MHC expression on glial cells in vitro [11], live virus was usually added on day 1 and day 2 although this did not result in an increase in the number of productively infected cells.

Double staining of infected cultures showed that MHC class I expression was significantly enhanced in both $\mathrm{GFAP}^{+}$(astrocyte, Table 2) and GFAP- (microglial) populations. The magnitude of this increase was similar for all populations. In contrast, any induction of MHC class II was virtually restricted to GFAP $^{+}$astrocytes (see below). ICAM-1/GFAP expression divided the mixed glial cultures
Table 2. Increased astrocyte MHC class I and ICAM-1 expression after MV infection ${ }^{a)}$

$\begin{array}{lcrrr} & \begin{array}{c}\text { Non-infected } \\ \text { (day 0) }\end{array} & \text { Day 1 } & \text { Day 2 } & \text { Day 3 } \\ \text { MHC class I } & 65^{\text {b) }}(239) & 74(386) & 90(849) & 96(788) \\ \text { MHC class II } & 2(156) & 4(113) & 10(166) & 7(206) \\ \text { ICAM-1 } & 64(420) & 61(398) & 83(571) & 90(465)\end{array}$

a) Uninfected cells from mixed glial cultures were examined for cell surface phenotype on day 0 of the experiment. MV was added to mixed glial cultures for $\mathbf{1 ~ h}$ on day 0 only and stained for FCM $24 \mathrm{~h}$ later (day 1 ), on day 0 and day 1 and examined 24 h later (day 2 ) or on day 0 , day 1 and day 2 and examined 24 h later (day 3).

b) Percentage positive GFAP ${ }^{+}$cells present within uninfected or infected mixed glial cultures. Figures in parentheses are mean fluorescence intensity. Thesc data are from a single experiment. MHC class I and ICAM- 1 levels shown here are highly representative of other comparable experiments. Percentage MHC class $\mathrm{II}^{+}$astrocytes was rarely higher than shown here and usually $<7 \%$ of cells were positive after infection. MHC class II fluorescence intensity levels were generally low and not enhanced by infection.

into four populations almost identical to that seen with MHC class I/GFAP (Fig. $2 \mathrm{c}$; see also Fig. 4 for ICAM-1 expression). Unlike MHC class I, however, MV infection only resulted in increased expression of ICAM-1 on astrocytes. Mean fluorescence intensity shifts for ICAM-1 after infection in one experiment were: GFAP $^{+}$cells, 311 to 465 and GFAP- (microglial) cells, 462 to 490 . In some cases the latter cell population did not shift at all. Thus, the data in Table 2 show only the changes in phenotype of astrocytes present within these mixed glial cultures. Enhanced MHC class I expression occurs rapidly, being evident by day 1 and normally peaking on day 2 . The magnitude of ICAM-1 augmentation after MV infection is not as substantial, increases are not seen until day 2 and, like MHC class I, ICAM-1 expression begins to reduce by day 3 .

MHC class II expression on $>15 \%$ of astrocytes was detected only in a minority of cases and more typical results are given in Table 2 and its legend. Addition of TNF- $\alpha$ together with virus did not further increase the expression of MHC class I, MHC class II or ICAM-1 (data not shown). Note that addition of low levels of IFN- $\gamma$ to our mixed glial cultures $(10 \mathrm{U} / \mathrm{ml}$ or less) induced high level expression of MHC class II on both astrocytes and microglia (data not shown).

\subsection{Expression of the intranuclear rat $\mathrm{Mx}$ protein and secretion of type-I IFN}

The possible release of type-I IFN by infected glial cells was investigated employing antibody recognizing rat $\mathbf{M x}$, a protein inducible by type-I IFN but not IFN- $\gamma[24,31]$. Fig. 3 and Table 3 show that $\mathrm{Mx}$ was induced in a high proportion of cells in mixed glial cultures after virus infection. In around $30 \%$ of infected cells, Mx was not detected but was highly induced in the surrounding cells (Fig. 3 a). The remaining infected cells were also $\mathrm{Mx}^{+}$. Two additional points should be noted. First, transfer of SN 
Table 3. Induction of $M x$ in mixed glial cells after. $M V$ infection $^{\text {a) }}$

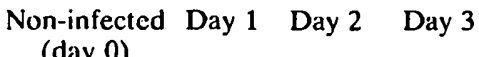
(day 0)

$\begin{array}{llrrr}\text { Mock infection } & 1^{\text {b) }} & 2 & 1 & 2 \\ \text { MV infection } & 1 & 54 & 60 & 51\end{array}$

a) Uninfected cells from mixed glial cultures were examined for Mx on day 0 of the experiment. MV was added to mixed glial cultures for $1 \mathrm{~h}$ on day 0 only and stained for FCM $24 \mathrm{~h}$ later (day 1 ), on day 0 and day 1 and examined $24 \mathrm{~h}$ later (day 2) or on day 0 , day 1 and day 2 and examined $24 \mathrm{~h}$ later (day 3 ).

b) Shown are percentage strongly $\mathrm{Mx}^{+}$cells within the total glial cell population. Data are typical of two other similar experiments.

from day 1 and day 2 infected cultures onto uninfected glial cells resulted in comparable levels of $\mathrm{Mx}$ induction. No virus-infected cells could be detected in these recipient
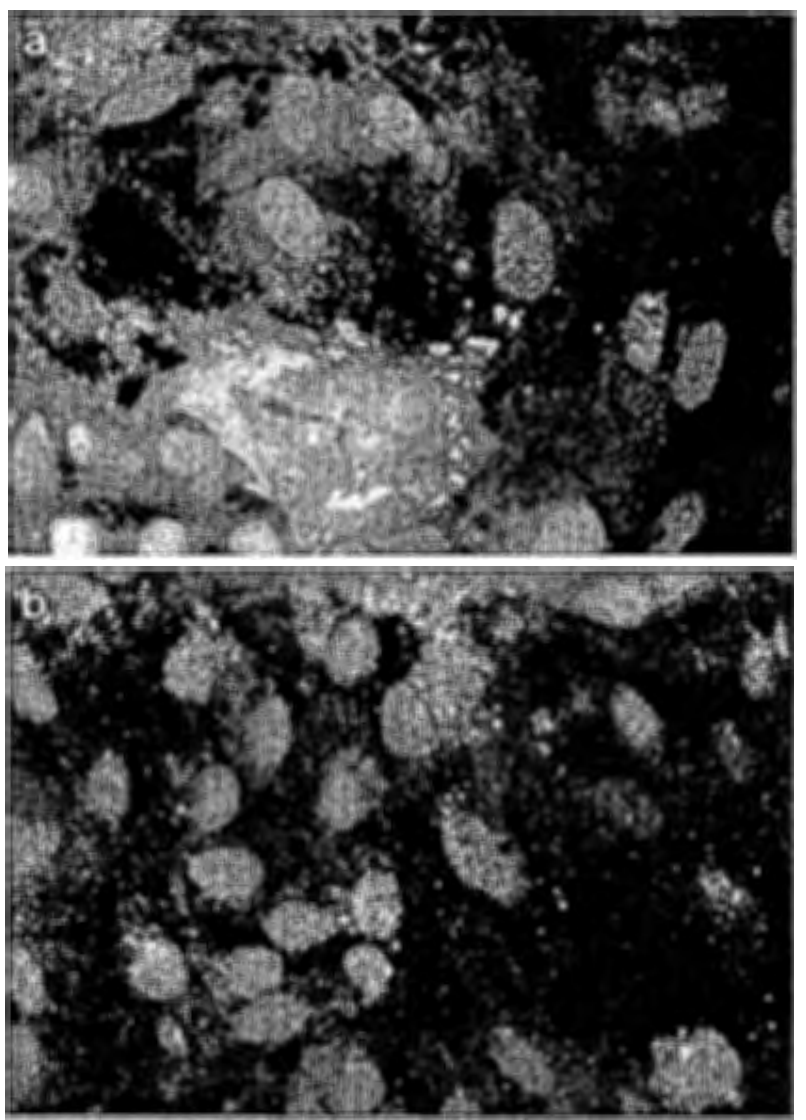

Figure 3. $\mathrm{Mx}^{+}$cells in virus-infected cultures. Double staining for viral antigen and $M x$ was achieved by first staining with F227 (anti-MV nucleocapsid) and FITC-anti-mouse IgG followed by addition of rabbit anti-rat Mx and TRITC-conjugated goat antirabbit IgG. (a) MV-infected mixed glial culture showing a single virus-infected cell (cytoplasmic staining of viral nucleocapsid) surrounded by $\mathrm{Mx}^{+}$cells which in this field are mostly astrocytes (nuclear staining). The infected cell is not $\mathrm{Mx}^{+}$in this case. (b) Mock-infected glial cell culture stained as in (a) for MV nucleocapsid and $\mathrm{Mx}$. cultures which is not surprising given previous studies [32] which found only very low levels $(0.01-0.001 \mathrm{PFU} /$ infected cell) of infectious virus present in glial cell $\mathrm{SN}$ obtained 24-48 h post MV infection. Second, treatment of mixed glial cultures with $10 \mathrm{U} / \mathrm{ml}$ rat type-I IFN induced a comparable increase in MHC class I and ICAM-1 expression on astrocytes but had no effect on MHC class II expression. Moreover, as illustrated in Fig. 4, the cell populations responding to type-I IFN were similar to those that responded after virus infection as discussed above. Thus, type-I IFN increased MHC class I expression on all cells in culture including $\mathrm{M} \Phi / \mathrm{microglial}$ cells (compare Fig. $4 \mathrm{a}$ with $4 \mathrm{c}$ where all populations shift to the right). In contrast, only "mature" GFAP+ ICAM-1+ cells (Fig. 4b and $4 \mathrm{~d}$, box 2) revealed an increased ICAM-1 expression and the magnitude of this increase was relatively low as seen also after MV infection (Table 2). Mean fluorescence intensity of the main GFAP ${ }^{+}$MHC class $\mathrm{I}^{+}$populations (box 2) are a, 174 and c, 572, and of the GFAP ${ }^{+}$ICAM-1 $^{+}$ populations are b, 311 and d, 421 .

In view of these results, preliminary attempts were made to determine whether the presence of blocking anti-type-1 IFN antibody would inhibit the augmentation of MHC class I and ICAM-1 following MV infection. Addition of polyclonal anti-rat type-I IFN to glial cultures treated with type-I IFN completely neutralized the MHC class I and ICAM-1 enhancing effect of the cytokine. However, addition of the same concentration of antibody to virus-infected cultures reduced to some extent the magnitude of MHC class I and ICAM-1 augmentation but did not completely eliminate it. The possible interpretations and implications of these studies are discussed below.

\subsection{Astrocytes from MV-infected cultures are more susceptible to MHC class I-restricted CTL}

To examine the functional impact of enhanced MHC class I and ICAM-1 levels on astrocytes, alloreactive CTL were generated and their ability to lyse enriched astrocytes derived from mock $v s$. infected cultures examined. The data shown in Fig. 5 a (Exp. 1) is a typical outcome demonstrating that at lower $E / T$ ratios, astrocytes from infected cultures were still lysed while those from mock-infected cultures were not. CTL activity was substantially reduced in the presence of $10 \mu \mathrm{g} / \mathrm{ml} \mathrm{mAb}$ specific for MHC class I and LFA- 1 but not with this concentration of $\mathrm{mAb}$ against MHC class II or ICAM-1 (Fig. $5 \mathrm{~b}$ ). The inability of the $1 \mathrm{~A} 29 \mathrm{mAb}$ against rat ICAM-1 to block CTL activity was unexpected in view of the fact that this concentration of $\mathrm{mAb}$ prevents cell-cell adhesion in vitro [21]. In a subsequent experiment to test whether this was due to a concentration effect (Exp. 2), a variation on the enhanced killing of virus-infected astrocytes was observed. Percent specific release was very high and there was enhancement of killing compared with mock-infected astrocytes at both high and lower E/T ratios (Fig. $5 \mathrm{c}$ ). The important aspect, however, was that doubling the concentration of antiICAM-1 mAb to $20 \mu \mathrm{g} / \mathrm{ml}$ resulted in effective CTL inhibition, whereas $20 \mu \mathrm{g} / \mathrm{ml}$ anti-MHC class II mAb still had no effect (Fig. 5d). CTL specificity was tested aginst T cell blasts. Typical specific ${ }^{51} \mathrm{Cr}$ release at a $1: 50$ ratio for syngeneic BDII blasts was $<1 \%$ and for allogeneic LEW blasts, around $40 \%$ 


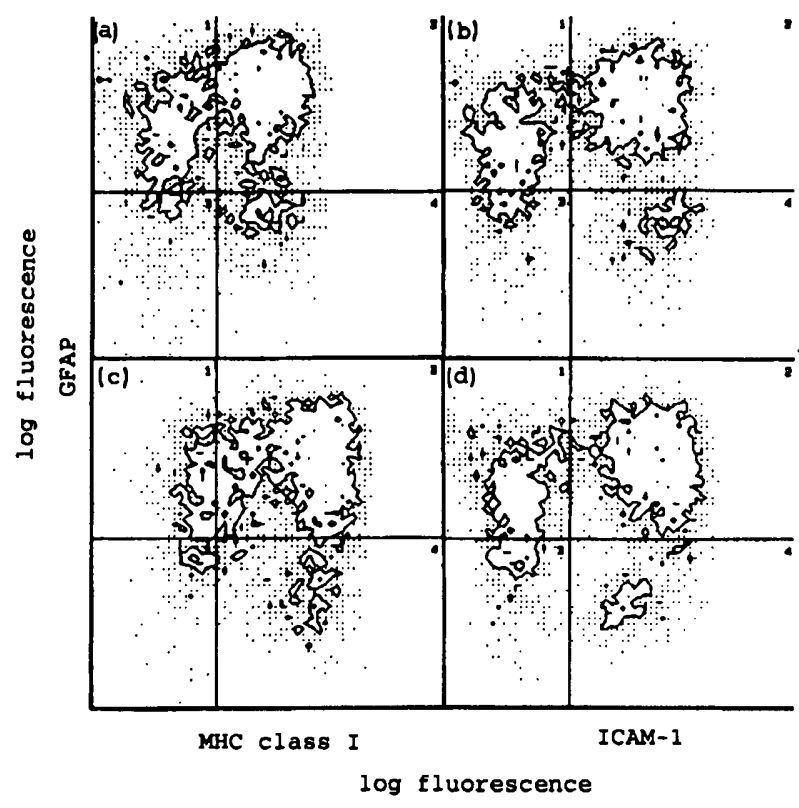

Figure 4. Alteration in astrocyte and microglial cell MHC class 1 and ICAM-1 expression after type-I IFN treatment. Mixed glial cells were left untreated $(\mathrm{a}, \mathrm{b})$ or incubated for $48 \mathrm{~h}$ in the presence of $10 \mathrm{U} / \mathrm{ml}$ type-I IFN (c, d) then the cells stained for MHC class I and ICAM-1.

\section{Discussion}

Increasing the expression levels of cell-surface molecules that are essential for $T$ cell recognition of virus-infected cells is obviously a critical step in the development of effective antiviral immune responses in the CNS. As demonstrated here and elsewhere for MHC molecules $[10-12,14]$ and for the first time for ICAM-1 (Table 2), it is apparent that enhanced expression may result from the virus infection itself, rather than in response to inflammatory cytokines. It is apparent moreover, that this has a functional impact in as much as an increased susceptibility of astrocytes from infected cultures to MHC class Irestricted CTL was consistently observed (Fig. 5). Yet the mechanisms by which cell surface molecule expression may be induced or augmented in situations such as that seen here, are not well understood.

There are at least three ways in which virus infection may influence the expression of cell surface molecules: (a) direct effect of the virus. Possibilities here include a virus transactivating gene product that influences cellular genes controlling expression of surface antigens [33, 34]; (b) virus-induced release of factors such as type-I IFN that act in an autocrine fashion onto the producing cell and (c) as per mechanism 2 but also acting on other cells [13]. With regard to the MV-mediated MHC and ICAM-1 enhancement observed here, there is as yet no evidence for the existence of a MV transactivating capacity. However, certain IFN-inducible genes have been shown to be induced directly by double-stranded RNA [35] or intact virus [36]. This raises the possibility that RNA viruses like MV may directly up-regulate the expression of surface molecules such as MHC class I in a similar way, particularly as there is significant sequence homology between the promoter regions of MHC class I and type-I IFN genes [37]. To date, however, no direct evidence is available that such a mechanism is operating here.

We believe that the presence of $\mathrm{Mx}$ in cultures infected with $\mathrm{MV}$ is a good indicator for the presence of type-I IFN and indeed, the SN transfer studies confirm that IFN had been secreted. Moreover, this same cytokine when added to glial cultures was capable of modifying MHC class I and ICAM1 expression (Fig. 4) in a comparable manner. Thus, it is likely that type-1 IFN is playing a central role in these experiments. Nevertheless, it is difficult to prove this mechanism unequivocally. As noted in Sect. 3, studies with blocking anti-IFN antibody did not effectively prevent MV-induced augmentation of surface molecule expression. On the one hand, this preliminary result could suggest that IFN is not involved and that MHC class I and ICAM-1 enhancement, and even $\mathrm{Mx}$ induction, are directly mediated by virus via mechanisms akin to those discussed above. However, there are major limitations to these

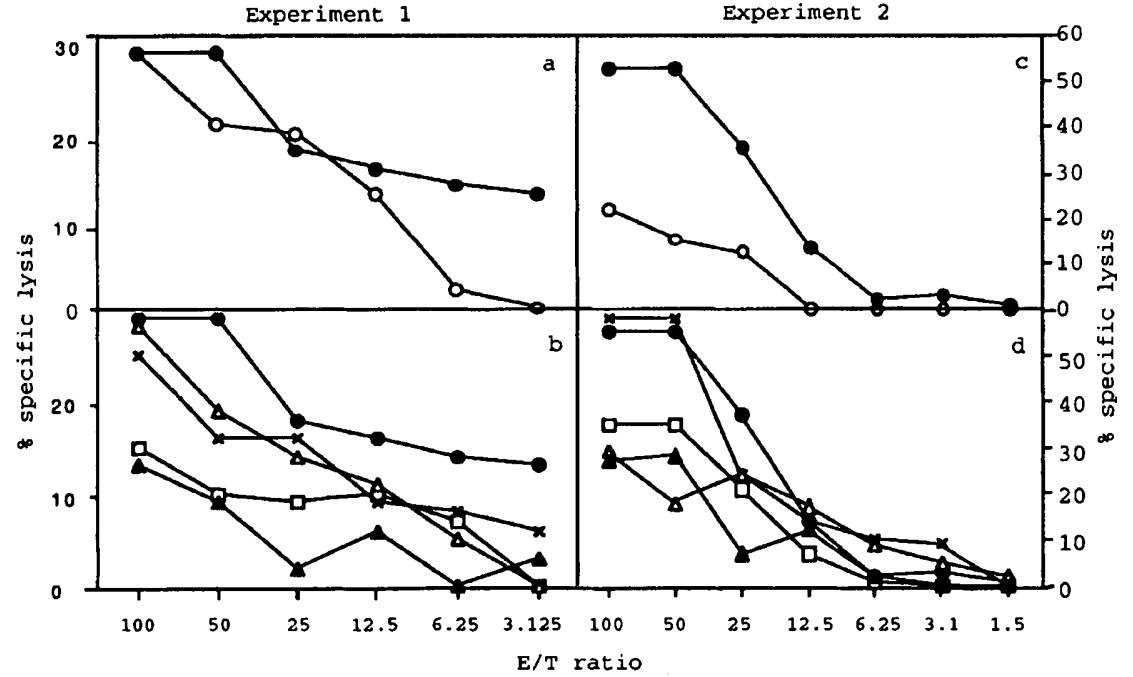

Figure 5. Increased susceptibility of MV-infected astrocytes to MHC class I-restricted CTL. BDII antiLEW alloreactive CTL were titrated onto $\operatorname{MV}(\boldsymbol{\bullet}, \square, \times, \triangle, \mathbf{A})$ or mockinfected (O) LEW astrocytes in the absence $(\mathrm{O}, \mathrm{)})$, or presence of $\mathrm{mAb}$ against rat MHC class I ( $\square$ ), MHC class II $(x)$, ICAM-1 $(\triangle)$ or LFA-1 $(\Delta)$. In experiment $1(a, b)$, all $m A b$ were at a final concentration of 10 $\mu \mathrm{g} / \mathrm{ml}$. In experiment 2 (c, d), antiMHC class I and LFA-1 were at 10 $\mu \mathrm{g} / \mathrm{ml}$ and anti-MHC class II and ICAM-1 were at $20 \mu \mathrm{g} / \mathrm{ml}$. 
inhibition studies. In particular, it is not clear how effectively antibodies may neutralize autocrine stimulation. For example, addition of high concentrations of anti-human IFN- $\beta$ antisera to $M V$-infected human glioma cells (which only secrete IFN- $\beta$ ), reduces the amount of detectable $\mathrm{Mx}-\mathrm{A}$ protein only by around $50 \%$ (S. Schneider-Schaulies, data not shown) and one can argue in this case either that the virus directly up-regulates $\mathrm{Mx}$ - $\mathrm{A}$ (for which there is no evidence), or that prevention of autocrine type-I IFN effects is lacking. We favor the latter of these two explanations. In the present experiments, enhanced surface antigen expression was observed on the majority of astrocytes in culture and yet, relatively few cells were still infected when the cells were analyzed at 24,48 and $72 \mathrm{~h}$. This could argue against the possibility of autocrine effects unless these were initiated within the first few hours after addition of virus when most cells were infected. Given the rapid appearance of $\mathrm{Mx}$ in virus-infected cultures (Table 3 ) and enhanced MHC class I expression already by day 1 (Table 2), it is probable that this did occur. Subsequently, there can be little doubt that many cells were further affected by soluble type-I IFN released from infected cells as evidenced by our observation of high $\mathrm{Mx}$ expression surrounding virus-infected cells (Fig. 3).

Release of type-I IFN by virus-infected cells does not readily explain the low level induction of MHC class II on astrocytes observed in some of our experiments and in studies by others $[11,12,14]$. Neutralizing antibodies have been used [11] to exclude the role of IFN- $\gamma$ in virusmediated induction of MHC class II although, as with the present studies with anti-type-I IFN antibodies, such an approach cannot entirely exclude autocrine effects. Nevertheless, it is most unlikely that IFN- $\gamma$ could be responsible because typical cellular sources of IFN- $\gamma$ such as T lymphocytes and NK cells are absent and there is no evidence that astrocytes (or microglia) produce it. Moreover, addition of IFN- $\gamma$ to mixed glial cultures induced MHC class II expression on both astrocytes and microglia, while after MV infection, only the former cell type became MHC class $\mathrm{II}^{+}$ at a very low level. It is notable that the levels of MHC class II induction were less than that observed previously with MV in a similar system [11]. This may be explained by the high levels of type-I IFN in our cultures as this cytokine is reported to inhibit MHC class II induction [38].

Opinions are divided concerning the relative importance of cytolytic $\mathrm{CD}^{+}{ }^{+}$[39] or $\mathrm{CD} 8^{+}$[40] $\mathrm{T}$ lymphocytes in the immunological control of MV infection. It is now clear that peptides derived from internal MV structural proteins can be presented by both MHC class I [41] and MHC class II molecules [42] and MV appears relatively unusual, although not unique [43] in this respect. In rat models of CNS MV infection, there is evidence for a central role for both cytolytic $\mathrm{CD}^{+}{ }^{+}[44]$ as well as $\mathrm{CD}^{+}$[45] T cells in control of infection. Nevertheless, with regard to elimination of CNS-associated virus, it would appear from the present studies that MHC class I is more likely to be enhanced on infected glial cells and in that sense, MHC class I-restricted CTL should more readily be able to recognize the infected target cell. Furthermore, in general, it is difficult to induce MHC class II in vivo on the typical target cells of MV in the CNS, such as astrocytes, neurons and oligodendrocytes although it is certainly possible that the low levels that are induced are sufficient to allow $\mathrm{CD}^{+}$ T cell recognition.

$\mathrm{Mx}-\mathrm{A}^{+}$cells have recently been detected in association with virus-infected cells in CNS tissue obtained postmortem from several subacute sclerosing panencephalitis patients (S. and J. Schneider-Schaulies, unpublished) indicating the secretion of type-I IFN in vivo. It is yet to be established whether this is also associated with increased expression of MHC and adhesion molecules. Moreover, one must somehow reconcile these latter observations and those presented in the present study, with the knowledge that in subacute sclerosing panencephalitis, there appears to be no particular defect in MV T cell responses, that there is often abundant nucleocapsid protein present in infected CNS cells, and yet the virus is not effectively eliminated [46].

Thanks are extended to Professor Volker Ter Meulen, Dr. Uwe Liebert and Stefan Niewiesk for helpful discussions, to Sieglinde Löffler and Susanne Hellmig for advice on $M V$ preparation and titration and to Hanne Weinand for technical assistance.

Received July 1, 1991; in final revised form September 5, 1991.

\section{References}

1 Schncider-Schaulies, S. and Ter Mculen, V., in Roos, R. P. (Ed.), Biological approaches to the siudy of CNS viral diseases, Humana Press, Clifton 1991, in press.

2 Hart, D. N. J. and Fabre, J. W., J. Exp. Med. 1981. 154: 347.

3 Cannella, B., Cross, A. H. and Raine, C. S., J. Exp. Med. 1990. 172: 1521 .

4 Sedgwick, J. D. and Dörries, R., Semin. Neurosci. 1991. 3: 93.

5 Doherty, P. C., Allan, J. E., Lynch, F. and Ceredig, R. Immunol. Today 1990. 11: 55.

6 Hickey, W. F., Hsu, B. L. and Kimura, H., J. Neurosci. Res. 1991. 28: 254 .

7 Wekerle, H., Linington, C., Lassmann, H. and Meyermann, R., Trends Neurosci. 1986. 9: 271.

8 Frohman, E. M., Frohman, T. C., Dustin, M. L., Vayuvegula, B., Choi, B., Gupta, A., Van den Noort, S. and Gupta, S., J. Neuroimmunol. 1989. 23: 117.

9 Flyer, D. C., Burakoff, S. J. and Faller, D.V., J. Immunol. 1985. 135: 2287.

10 Suzumura, A., Lavi, E., Weiss, S. R. and Silberberg, D. H., Science 1986. 232: 991.

11 Massa, P. T., Schimpl, A.,Wecker, E. and Ter Meulen, V., Proc. Natl. Acad. Sci. USA 1987. 84: 7242.

12 Liu, Y., King, N., Kesson, A., Blanden, R. V. and Müllbacher, A., J. Neuroimmunol. 1989. 21: 157.

13 Maudsley, D. J., Morris, A. G. and Tomkins, P.T., in Dimmock, N. J. and Minor, P. D. (Eds.), Immune responses, virus infections and disease, IRL Press, Oxford 1989, p. 15.

14 Massa, P.T., Dörries, R. and Ter Meulen, V., Nature 1986. 320: 543.

15 Sunderland, C. A., McMaster, W. R. and Williams, A. F., Eur. J. Immunol. 1979. 9: 155

16 McMaster,W. R. and Williams, A. F., Eur. J. Immunol. 1979. 9: 426.

17 Fukumoto, T., McMaster, W. R. and Williams, A. F., Eur. J. Immunol. 1982. 12: 237.

18 Hsiung, J.., Barclay, A. N., Brandon, M. R., Sim, E. and Porter, R. R., Biochem. J. 1982. 203: 293

19 Robinson, A. P., White, T. M. and Mason, D. W., Immunology 1986. $57: 239$ 
20 Tamatani, T., Kotani, M. and Miyasaka, M., Eur. J. Immunol. 1991. 21: 627

21 Tamatani, T. and Miyasaka, M., Int. Immunol. 1990. 2: 165.

22 Ranscht, B., Clapshaw, P. A., Price, J., Noble, M. and Siefert, W., Proc. Natl. Acad. Sci. USA 1982. 79: 2709.

23 Mason, D. W., Penhale, W. J. and Sedgwick, J. D., in Klaus, G. G. B. (Ed.), Lymphocytes; a practical approach, IRL Press Ltd., Oxford 1987, p. 35.

24 Meier, E., Fäh, J., Grob, M. S., End, R., Staeheli, P. and Haller, O., J. Virol. 1988. 62: 2386.

25 Bigner, D. D., Bigner, S. H., Pontén, J., Westermark, B., Mahaley, M. S. J., Ruoslahti, E., Herschman, H., Eng, L. F. and Wikstrand, C. J., J. Neuropathol. Exp. Neur. 1981. 40: 210.

26 Sedgwick, J. D., Schwender, S., Imrich, H., Dörries, R. Butcher, G.W. and Ter Meulen, V., Proc. Natl. Acad. Sci. USA 1991. 88: 7438.

27 Massa, P.T., Ter Meulen, V. and Fontana, A., Proc. Natl. Acad. Sci. USA 1987. 84: 4219.

28 Halldén, G., Andersson, U., Hed, J. and Johansson, S. G. O., J. Immunol. Methods 1989. 124: 103.

29 Raff, M. C., Miller, R. H. and Noble, M., Nature 1983. 303 390.

30 Sedgwick, J. D., Mößner, R., Schwender, S. and Ter Meulen,V. J. Exp. Med. 1991. 173: 1235.

31 Von Wussow, P., Jakschies, D., Hochkeppel, H.-K., Fibich, C. Penner, L. and Deicher, H., Eur. J. Immunol. 1990. 20 2015.

32 Schneider-Schaulies, S., Liebert, U. G., Baczko, K. and Ter Meulen, V., Virology 1990. 177: 802.
33 Greene,W. C., Leonard, W. J.,Wano, Y., Svetlik, P. B., Peffer, N. J., Sodroski, J. G., Rosen, C. A., Goh, W. C. and Haseltine, W. A., Science 1986. 232: 877

34 Kannagi, M., Kiyotaki, M., King, N.W., Lord, C. I. and Letvin, N. L., J. Virol. 1987. 61: 1421.

35 Tiwari, R. K., Kusari, J. and Sen, G. C., EMBO J. 1987. 6: 3373.

36 Hug, H., Costas, M., Stacheli, P., Aebi, M. and Weissmann, C., Mol. Cell Biol. 1988. 8: 3065.

37 Fan, C.-M. and Maniatis, T., EMBO J. 1989. 8: 101.

38 Barna, B. P., Chou, S. M., Jacobs, B., Yen-Lieberman, B. and Ransohoff, R. M., J. Neuroimmunol. 1989. 23: 45.

39 Jacobson, S., Richert, J. R., Biddison, W. E., Satinsky, A., Hartzman, R. J. and McFarland, H. F., J. Immunol. 1984. 133: 754.

40 Lucas, C. J., Biddison, W. E., Nelson, D. L. and Shaw, S., Infect. Immun. 1982. 38: 226.

41 Van Binnendijk, R. S., Poelen, M. C. M., Kuijpers, K. C. Osterhaus, A. D. M. E. and Uytdehaag, F. G. C. M., J. Immunol. 1990. 144: 2394.

42 Jacobson, S., Sekaly, R. P., Jacobson, C. L., McFarland, H. F. and Long, E. O., J. Virol. 1989. 63: 1756.

43 Nuchtern, J. G., Biddison, W. E. and Klausner, R. D., Nature 1990. 343: 74

44 Maehlen, J., Olsson, T., Löve, A., Klareskog, L., Norrby, E. and Kristensson, K., J. Neuroimmunol. 1989. 21: 149.

45 Bankamp, B., Brinckmann, U. G., Reich, A., Niewiesk, S., Ter Meulen, V. and Liebert, U. G., J. Virol. 1991. 65: 1695.

46 Schneider-Schaulies, S. and Liebert, U. G., Semin. Neurosci. 1991. 3: 149 . 